\title{
Penoplasty for buried penis in infants and children: report of 100 cases
}

\author{
Lena Perger · Robert S. Hanley $\cdot$ Neil R. Feins
}

Published online: 13 December 2008

(C) Springer-Verlag 2008

\section{Erratum to: Pediatr Surg Int}

\section{DOI 10.1007/s00383-008-2283-9}

Due to errors in typesetting, the images in Figs. 2, 3, 4, 5, 6,7 , and 8 were all in the wrong positions, so that the illustrations did not match the legends. The correctly matched figures and legends are presented here.

The online version of the original article can be found under doi:10.1007/s00383-008-2283-9.

\section{Perger}

Department of Surgery, University of New Mexico Health

Sciences Center, Albuquerque, NM, USA

e-mail: lperger@gmail.com

\section{R. S. Hanley}

Department of Urology, Lahey Clinic,

Tufts University School of Medicine,

Burlington, MA, USA

\section{N. R. Feins $(\bowtie)$}

Department of Surgery, Children's Hospital Boston,

Harvard Medical School, Fegan 3, 300 Longwood Avenue,

Boston, MA 02115, USA

e-mail: neil.feins@childrens.harvard.edu

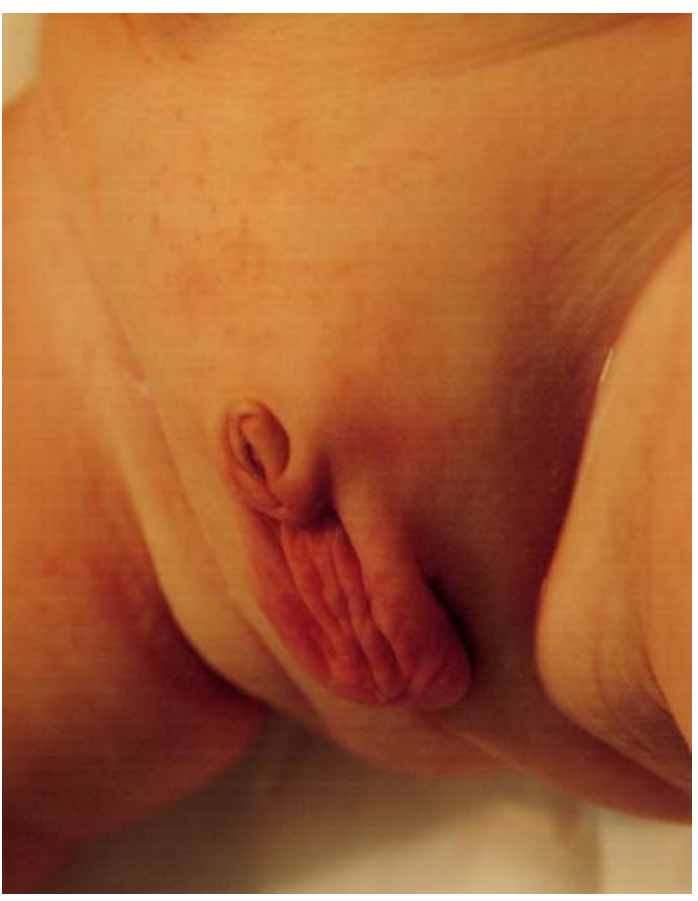

Fig. 2 Buried penis in a 6-month-old boy 


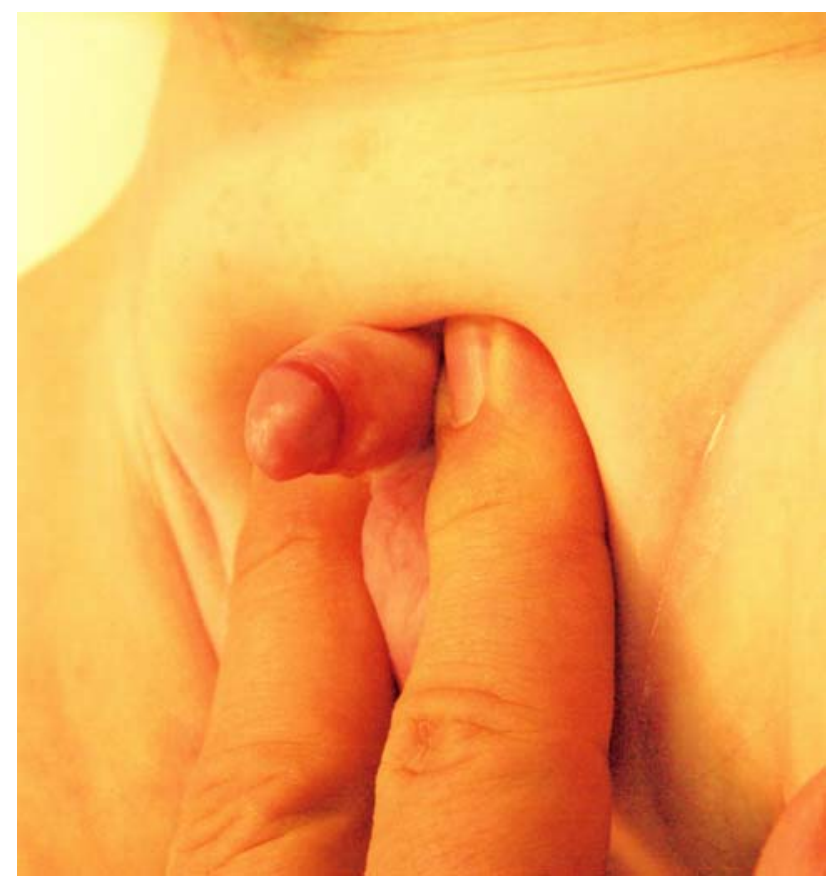

Fig. 3 Normal phallus exposed by application of pressure at the base of penile shaft

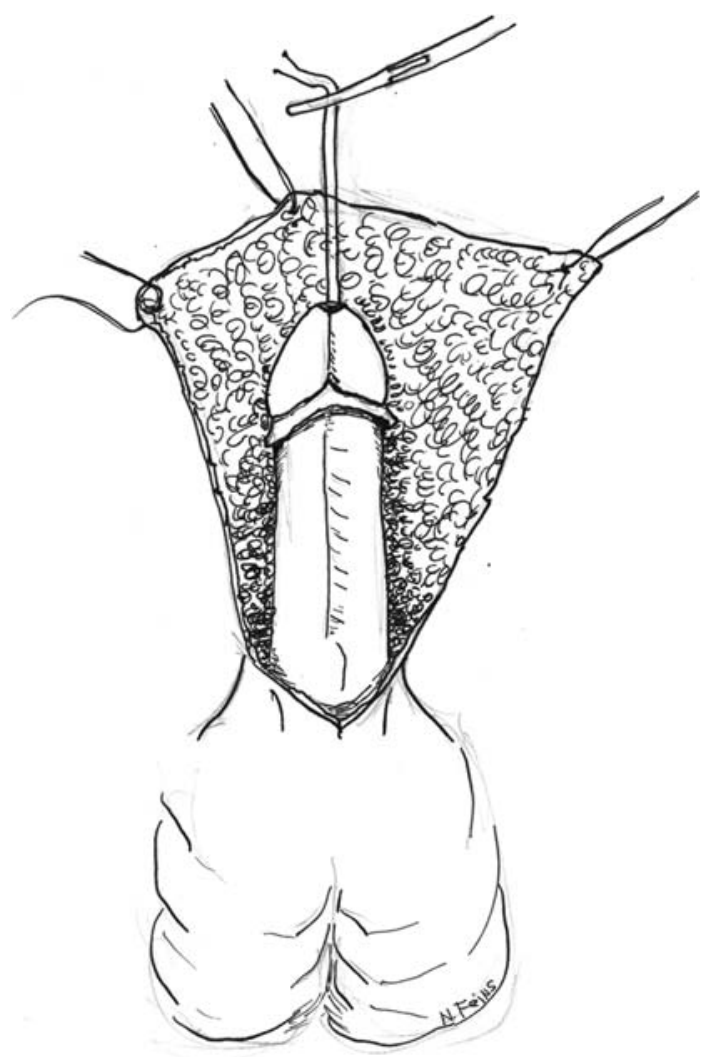

Fig. 4 Circumferential degloving of penis and development of preputial flap

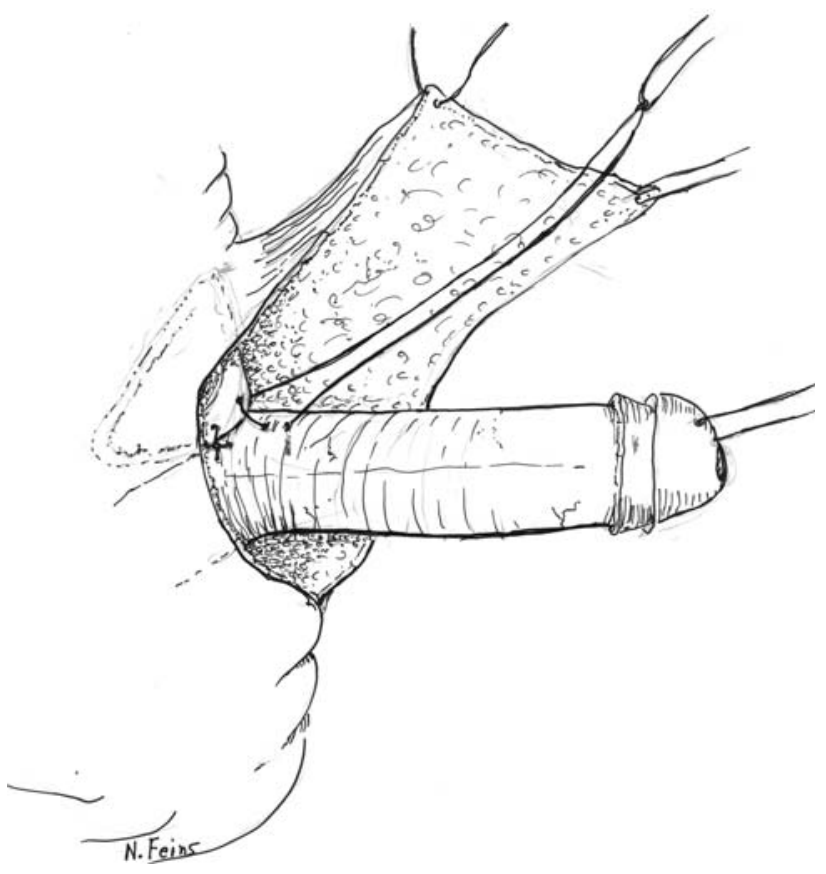

Fig. 5 Suturing of dorsal penile shaft base to prepubic fascia

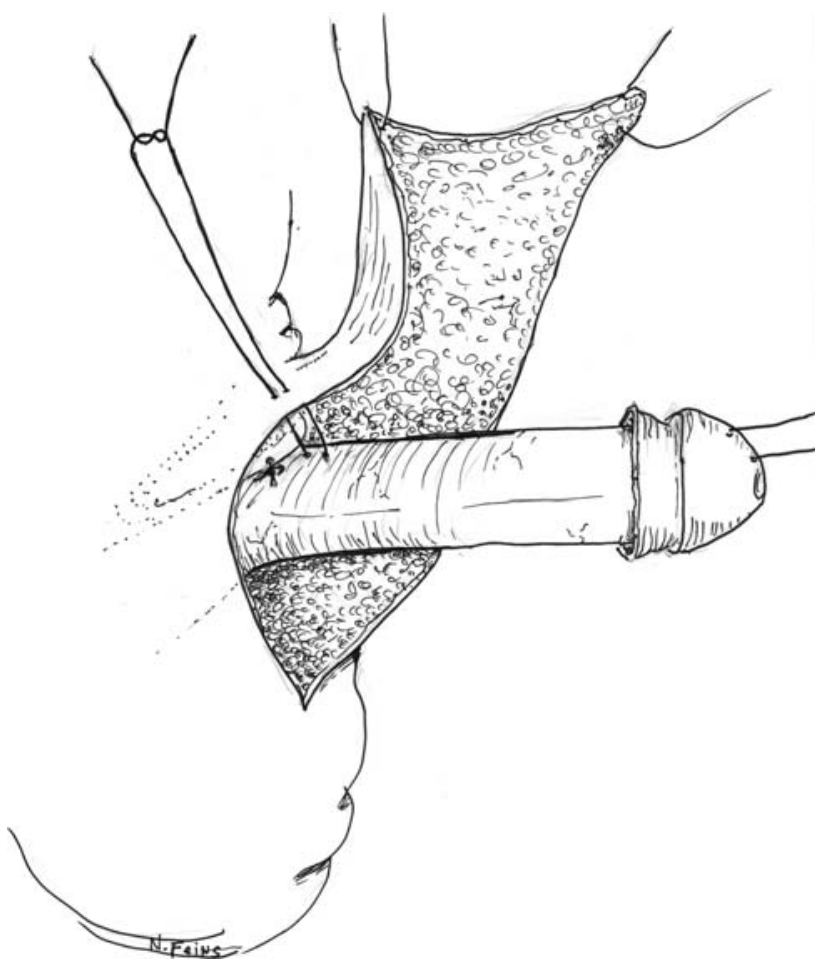

Fig. 6 Attachment of shaft skin to base of penile shaft with fullthickness vertical mattress sutures 


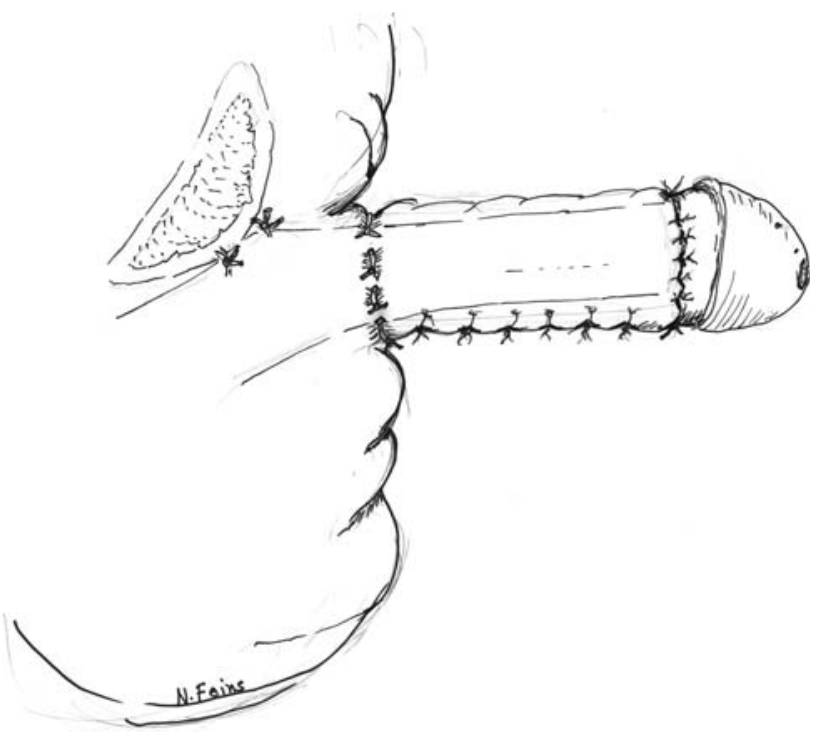

Fig. 7 Covering of penile shaft with skin, closure of mucosal collar

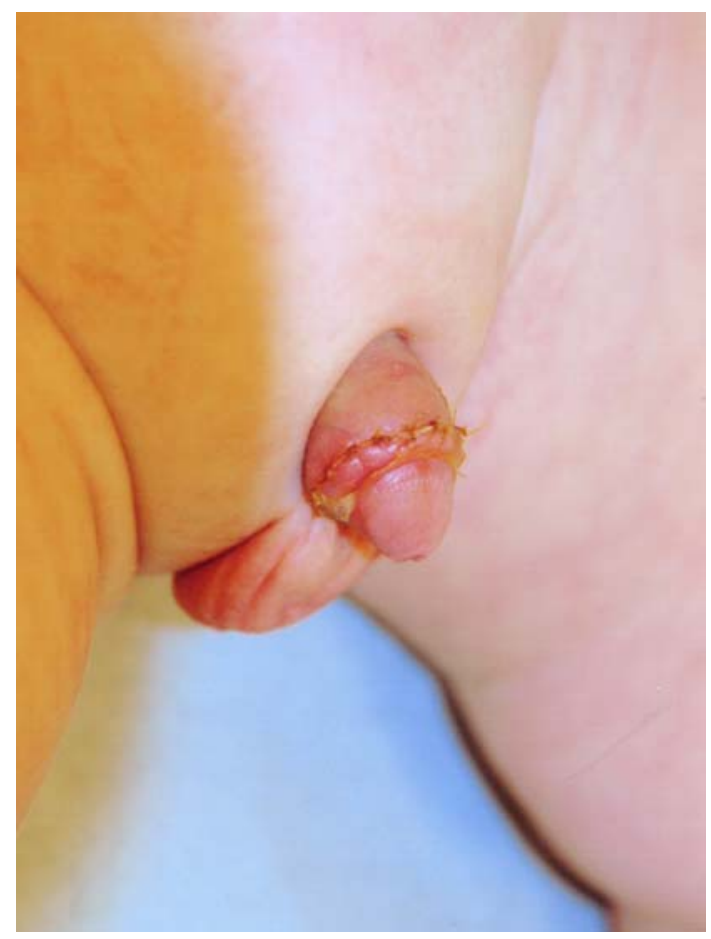

Fig. 8 Improved exposure of penis 2 weeks after surgery 